\title{
Factors influencing the decline in lung density in a Danish lung cancer screening cohort
}

\author{
Saher B. Shaker*, Asger Dirksen*, Pechin Lo", Lene T. Skovgaard", \\ Marleen de Bruijne ${ }^{\#,+}$ and Jesper H. Pedersen ${ }^{\S}$
}

ABSTRACT: Lung cancer screening trials provide an opportunity to study the natural history of emphysema by using computed tomography (CT) lung density as a surrogate parameter.

In the Danish Lung Cancer Screening Trial, 2,052 participants were included. At screening rounds, smoking habits were recorded and spirometry was performed. CT lung density was measured as the volume-adjusted 15th percentile density (PD15). A mixed effects model was used with former smoking males with $<\mathbf{3 0}$ pack-yrs and without airflow obstruction (AFO) at entry as a reference group.

At study entry, 893 (44\%) participants had AFO. For the reference group, PD15 was $72.6 \mathrm{~g} \cdot \mathrm{L}^{-1}$ with an annual decline of $-0.33 \mathrm{~g} \cdot \mathrm{L}^{-1}$. Female sex and current smoking increased PD15 at baseline, $17.3 \mathrm{~g} \cdot \mathrm{L}^{-1}(\mathrm{p}<0.001)$ and $10 \mathrm{~g} \cdot \mathrm{L}^{-1}(\mathrm{p}<0.001)$, respectively; and both increased the annual decline in PD15 (female: $-0.3 \mathrm{~g} \cdot \mathrm{L}^{-1}$; current smoking: $-0.4 \mathrm{~g} \cdot \mathrm{L}^{-1}$ ). The presence and severity of AFO was a strong predictor of low PD15 at baseline (Global Initiative for Chronic Obstructive Lung Disease (GOLD) I: $-1.4 \mathrm{~g} \cdot \mathrm{L}^{-1}$; GOLD II: $-6.3 \mathrm{~g} \cdot \mathrm{L}^{-1}$; GOLD III: $-17 \mathrm{~g} \cdot \mathrm{L}^{-1}$ ) and of increased annual decline in PD15 (GOLD I: $-0.2 \mathrm{~g} \cdot \mathrm{L}^{-1}$; GOLD II: $-0.5 \mathrm{~g} \cdot \mathrm{L}^{-1}$; GOLD III: $-0.5 \mathrm{~g} \cdot \mathrm{L}^{-1}$ ).

Female sex, active smoking and the presence of AFO are associated with accelerated decline in lung density.

KEYWORDS: Chronic obstructive pulmonary disease, densitometry, emphysema, quantitative computed tomography, smoking

$\mathbf{T}$ he mortality and morbidity of chronic obstructive pulmonary disease (COPD) is increasing worldwide. COPD, in which tobacco smoke is the single biggest risk factor, accounts for about 400,000 deaths annually in industrialised countries [1]. In COPD, loss of lung tissue due to emphysema is a major component. Measurement of lung density by computed tomography (CT) is a surrogate marker for emphysema and reflects both disease severity [2-4] and physiological impairment [5-6]. Crosssectional studies of the influence of smoking on lung density by CT have reported inconsistent results, with some researchers finding no influence of smoking habit on lung density [7], while others report decreased lung density with increasing pack-yrs [8-9]. This is not surprising given the fact that smoking has opposing effects on lung density. On one hand, current smoking triggers inflammation [10] that increases lung density [11], and on the other hand, smoking results in emphysema and decreased lung density in a substantial minority of smokers.
There is no evidence from longitudinal studies that smoking cessation halts or slows down the progression of emphysema. In recent studies, we have shown that smoking cessation is associated with decrease in lung density [11-12]; nevertheless, the influence on lung density changes of the burden of smoking, continuing smoking and the number of cigarettes smoked is largely unknown. In this regard, lung cancer screening trials with annual CT of the lungs provides a unique opportunity to study the influence of various factors on lung density including smoking habits and the presence and severity of airflow obstruction (AFO). In Denmark, we conducted a lung cancer screening trial [13], in which half of the 4,104 participants were randomised to annual CT of the lungs for 5 yrs between 2005 and 2009 . These and similar data from ongoing lung cancer screening trials provide invaluable insight into the pathophysiology and natural history of COPD.

The literature on quantitative CT of emphysema is extensive, consisting primarily of cross-sectional

\section{AFFILIATIONS}

*Dept of Respiratory Medicine, Gentofte Hospital, Hellerup, and \#Dept of Computer Science (DIKU), University of Copenhagen,

"Dept of Biostatistics, University of Copenhagen, and

${ }^{\text {s}}$ Dept of Thoracic Surgery RT, Rigshospitalet, University of

Copenhagen, Copenhagen, Denmark. ${ }^{+}$Depts of Medical Informatics and Radiology, Erasmus MC Rotterdam, Rotterdam, The Netherlands.

CORRESPONDENCE

S.B. Shaker

Dept of Respiratory Medicine

Gentofte Hospital

Niels Andersens vej 65

Hellerup

DK-2900

Denmark

E-mail: saher@dadlnet.dk

Received:

Nov 272011

Accepted after revision:

Feb 102012

First published online:

March 092012

Online ISSN 1399-3003 
descriptive studies because of the challenge imposed by lung volume changes during repeated scans. Change in lung volume is the most important confounder of the measurement of emphysema by CT resulting in poor reproducibility. To overcome this obstacle, we have applied statistical modelling to standardise lung density to lung volume both derived from the same scan, and in this way reduce measurement variations [14]. Using this method, we have shown a significant progression of emphysema [15] with a clear time trend that is superior to lung function measures [16]. In the current study, we used data from the Danish Lung Cancer Screening Trial (DLCST) and applied statistical modelling to adjust for lung volume changes between scans to study the influence of age, sex, smoking habits and the presence and degree of AFO on the decline in CT lung density.

\section{MATERIAL AND METHODS Study population}

The study population represents those participants randomised to annual low-dose CT in the DLCST [13], which is a 5-yr trial investigating the effect of screening on lung cancer mortality. Individuals volunteered for the trial in response to advertisements in local free newspapers. From October 2004 to March 2006, 4,104 participants were enrolled and randomised to either annual low-dose CT or a control group, who were not offered CT screening. Participants in the DLCST were males and females who were 50-70 yrs of age without lung cancer related symptoms. Other inclusion criteria were: a history of cigarette smoking of at least 20 pack-yrs; current or ex-smoker; exsmokers had to have quit after the age of 50 yrs and less than 10 yrs ago; forced expiratory volume in $1 \mathrm{~s}$ (FEV1) of at least $30 \%$ predicted normal at baseline; and provision of a written informed consent. Exclusion criteria were: body weight $>130 \mathrm{~kg}$; previous treatment for lung cancer, breast cancer, malignant melanoma or hypernephroma; any other malignancies within the last 5 yrs; tuberculosis within the last 2 yrs; or any serious illness that would shorten life expectancy to $<10$ yrs. In addition, measurements from individuals who changed their smoking habit during the study were excluded from the current analysis from the date of change of smoking habit.

In the screening group, 2,052 current or ex-smokers aged 5070 yrs were screened annually for 5 yrs (2005-2009) with lowdose CT. At annual screening rounds, smoking habits were recorded, the carbon monoxide level in exhaled breath was measured and spirometry was performed.

The DLCST is funded by a government grant and was approved by the regional ethics committee. The trial is performed in one institution: Gentofte Hospital in Copenhagen, Denmark. A detailed description of the study design and study population of the DLCST has been previously published [13].

\section{Imaging}

All CT scans were performed on the same multi-detector CT scanner with 16 detector rows (Philips Mx 8000; Philips Medical Systems, Eindhoven, the Netherlands). Scans were performed in the supine position at full inspiration with a caudocranial direction including the whole lungs. Participants were instructed by voice recordings to take a deep breath and to hold their breath during scanning (10-12 s), and then when the scan was completed to breathe normally again. A low-dose technique was applied (120 kV and $40 \mathrm{mAs}$ ) with the following acquisition parameters: field of view $40 \mathrm{~cm}$; collimation $16 \times 0.75 \mathrm{~mm}$; rotation time $0.5 \mathrm{~s}$; and pitch 1.5 . Images were reconstructed with $3 \mathrm{~mm}$ slice thickness using a soft reconstruction algorithm (kernel A). The scanner was usually maintained, qualitycontrolled and calibrated daily for air and at regular intervals for water according to the manufacturer's recommendations.

\section{Image analysis}

All CT scans were analysed by the Image Group at the Dept of Computer Science, University of Copenhagen (Copenhagen, Denmark) using in-house developed software designed to segment the lung and calculate various densitometric parameters [17]. The lung segmentation algorithm starts by detecting the trachea in the top slice. A special region growing algorithm segments the trachea down to the main carina. This region is not included in the calculations. Subsequently, the lungs are segmented starting from the main bronchi using a competing region growing algorithm and a threshold of $-400 \mathrm{HU}$ for the interface between lung and extrapulmonary tissue. The whole analysis is fully automated.

In a previous publication [11], the validity of the segmentation process was assessed by two physicians independently checking the segmentation of a sample of 200 CT scans. The observers checked whether the right and left lungs were correctly segmented and whether air from surrounding structures such as the oesophagus or bowel were erroneously included. Problems were encountered in $4 \%$ of segmentations and were all minor, corresponding to a CT volume $<1 \mathrm{~mL}$, except for one case in which $40 \mathrm{~mL}$ of bowel air was included in lung segmentation. No error in the separation of left and right lung was encountered in the reviewed scans.

From the segmented area, the total lung volume (TLV) was calculated. A frequency distribution of voxel densities (histogram) was generated from which the 15 th percentile density (PD15) was extracted as the density in $\mathrm{g} \cdot \mathrm{L}^{-1}$ at which $15 \%$ of the voxels have lower densities. Density values were converted into $\mathrm{g} \cdot \mathrm{L}^{-1}$ by adding 1,000 to the density value in $\mathrm{HU}$ (e.g. PD15 value of $-920 \mathrm{HU}$ equals $80 \mathrm{~g} \cdot \mathrm{L}^{-1}$ ).

Lung density is expressed as the volume-adjusted PD15 throughout this paper. Changes in lung volume have substantial influence on lung density, which more than doubles from full inspiration to full expiration; therefore, PD15 was adjusted for the change in inspiration level between scans by physiological modelling using a so called "sponge model" [18]. From a theoretical point of view, the lungs could be considered a sponge-like structure, in which a proportional decrease in lung volume would yield an equally proportional increase in density, as compression would be mass-preserving. As a result, the product of PD15 and TLV is constant and independent of the level of inspiration, and therefore we can adjust PD15 to the predicted total lung capacity (TLC) by multiplying PD15 by TLV and dividing by predicted TLC [14].

\section{Lung function tests}

Spirometry was performed annually on all participants according to recommendations by the European Respiratory Society using electronic spirometers (Spirotrac IV; Vitalograph, Buckingham, UK). Results are expressed in absolute values and as per cent 
of predicted normal values according to European reference equations [19].

\section{Statistics}

The influence of age, sex, smoking and AFO on PD15 was analysed in a linear mixed effects model with random intercept and random linear effect of age (slope over time). Former smoking males, with no AFO and 20-30 pack-yrs at entry to the screening study, were chosen as a reference group. A linear decline in PD15 over time was assumed and the time point corresponding to age $60 \mathrm{yrs}$ was used for cross-sectional comparisons. Furthermore, interactions between age (the time variable) and sex, smoking and AFO were included in the model as indications of the influences of these variables on the change of PD15 over time (that is the slopes in fig. 1). Because an interaction between age and another covariate indicates an influence on slope, it is interesting from a clinical point of view, and we decided to include these interactions in our model even if they were not statistically significant. Several other interactions between various covariates were tested as well, but none of them reached statistical significance, and they were not included in the final model.

We used a random coefficients model with linear time/age effect, allowing the intercept and slope to vary between subjects. It takes the form $Y_{i j}=\alpha_{i}+\beta_{i} t_{i j}+e_{i j}$ where $\alpha_{i}$ and $\beta_{i}$ are the individual intercept and slope associated with subject $i, t_{i j}$ is the age of subject $i$ at the time of the jth CT scan, and $Y_{i j}$ is the corresponding CT lung density (PD15) at this time. The $\mathrm{e}_{\mathrm{ij}}$ are independent random errors associated with $\mathrm{Y}_{\mathrm{ij}}$ and are normally distributed with mean 0 . The effects of covariates on the intercept and slope are modelled via $\alpha_{\mathrm{i}}=\alpha+\delta_{11} \times \mathrm{X}_{1 \mathrm{i}}+\delta_{12} \times \mathrm{X}_{2 \mathrm{i}}$ $+\ldots+\delta_{1 \mathrm{k}} \times \mathrm{X}_{\mathrm{ki}}+\mathrm{a}_{\mathrm{i}}$ and $\beta_{\mathrm{i}}=\beta+\delta_{21} \times \mathrm{X}_{1 \mathrm{i}}+\delta_{22} \times \mathrm{X}_{2 \mathrm{i}}+\ldots+\delta_{2 \mathrm{k}} \times \mathrm{X}_{\mathrm{ki}}$ $+b_{i}$ where $\alpha$ and $\beta$ are fixed population effects (intercept and slope), $X_{m}$ are the $m=1, \ldots, k$ covariates of interest, $\delta_{1 \mathrm{~m}}$ and $\delta_{2 \mathrm{~m}}$ are the $m=1, \ldots, k$ coefficients associated with the covariates, and $a_{i}$ and $b_{i}$ are the random intercept and slope for subject $i$. The random effects $a_{i}$ and $b_{i}$ for the same subject may be

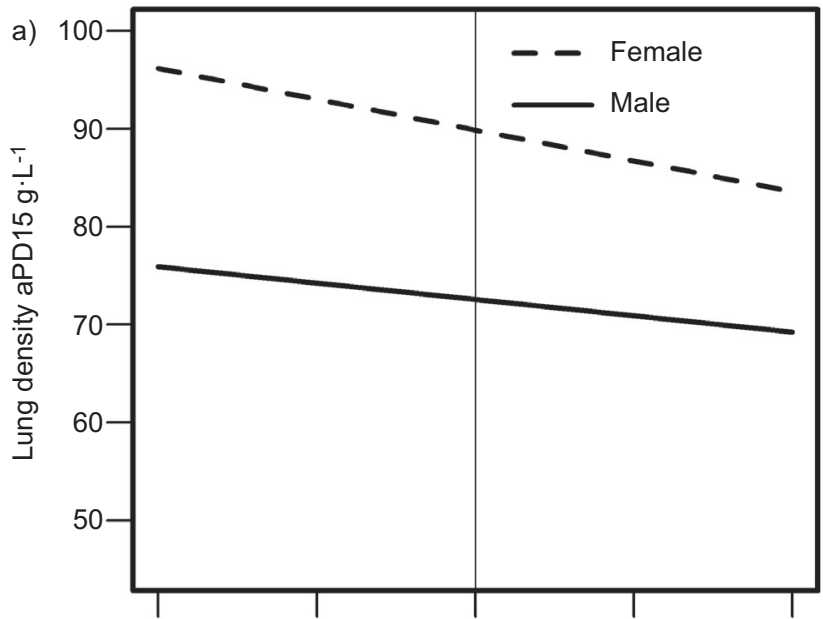

b)
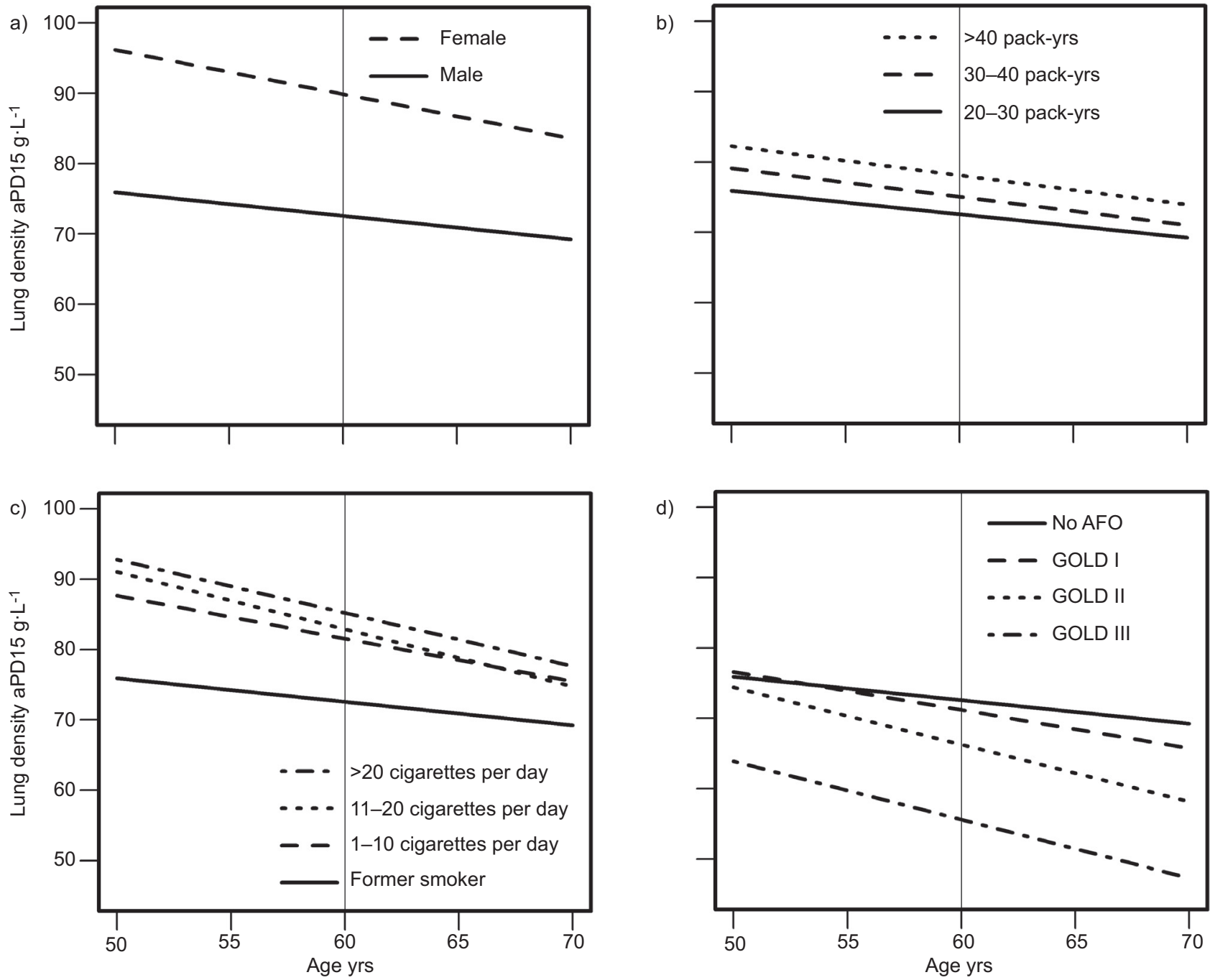

d)

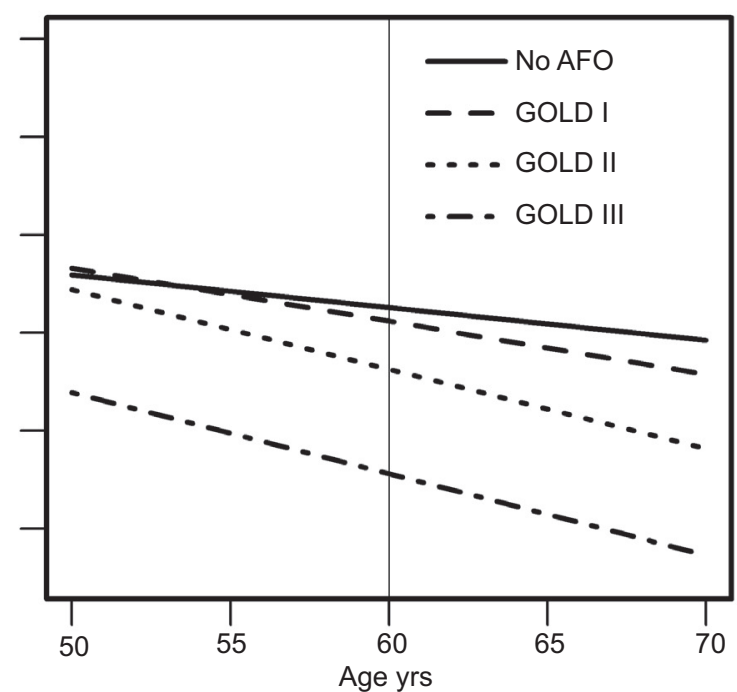

FIGURE 1. The influence of various factors on lung density by computed tomography. a) Sex, b) accumulated previous smoking (pack-yrs), c) current smoking status and d) presence and degree of airflow obstruction (AFO). Solid lines represent a reference group of former smoking males without AFO and with 20-30 pack-yrs at entry to the study. aPD15: adjusted 15th percentile density; GOLD: Global Initiative for Chronic Obstructive Lung Disease. 
dependent, but it is assumed that each of them is independently, normally distributed with mean 0 across subjects.

\section{RESULTS}

\section{Patient characteristics}

The characteristics of the study population of the DLCST are comprehensively described elsewhere [13]. The number of participants in the screening group in the DLCST was 2,052. Of those, 10 participants were excluded from the current analysis, because they withdrew after randomisation but before undergoing a CT scan. The baseline characteristics of the 2,042 participants included are shown in table 1 . There were 1,142 $(56 \%)$ males in the screening group. The mean \pm SD age was $57.9 \pm 4.8 \mathrm{yrs}$, and males were on average $0.9 \mathrm{yrs}$ older than females $(\mathrm{p}<0.001)$. All participants were heavy current 1,549 $(76 \%)$ or ex-smokers $493(24 \%)$ with a mean smoking history of $36.4 \pm 13.4$ pack-yrs with males having smoked on average 6 pack-yrs more than females $(\mathrm{p}<0.001)$. For current smoking, the median tobacco consumption on entry to the trial was 20 cigarettes per day (range 1-65) with males smoking slightly more than females. Throughout the 5-yr screening period $1,134(56 \%)$ participants remained active smokers, $424(21 \%)$ remained ex-smokers and $484(24 \%)$ changed their smoking habit (403 (20\%) restarted and $81(4 \%)$ stopped). At baseline, AFO defined as FEV1 / forced vital capacity $<0.7$ was detected in $892(44 \%)$ participants, of those $574(64 \%)$ were in Global Initiative for Chronic Obstructive Lung Disease (GOLD) stage I; 291 (33\%) in GOLD stage II; and 27 (3\%) in GOLD stage III. Only one participant did not have valid spirometry data. There were no participants in GOLD stage IV as they were excluded from the study because if the screen detected lung cancer they could not be offered surgery.

\section{Influence of age and sex on CT lung density}

A total of 8,063 CT scans were obtained and analysed. Throughout the paper, all subsequent comparisons are made to the reference group mentioned in the statistics section. $\mathrm{PD} 15 \pm \mathrm{SE}$ in the reference group was $72.6 \pm 0.8 \mathrm{~g} \cdot \mathrm{L}^{-1}$ at age $60 \mathrm{yrs}$ with an annual decline of $-0.33 \pm 0.09 \mathrm{~g} \cdot \mathrm{L}^{-1}(\mathrm{p}<0.001)$.

\begin{tabular}{|c|c|c|c|c|c|}
\hline TABLE 1 & $\begin{array}{l}\text { Charact } \\
\text { the trial }\end{array}$ & eristics of th & ie study pc & opulation a & entry to \\
\hline \multirow[t]{2}{*}{ Variable } & \multicolumn{2}{|c|}{$\begin{array}{l}\text { No airflow } \\
\text { obstruction }\end{array}$} & \multicolumn{2}{|c|}{ Airflow obstruction } & \multirow[t]{2}{*}{ All } \\
\hline & Males & Females & Males & Females & \\
\hline Subjects n & 643 & 506 & 499 & 394 & 2042 \\
\hline Age yrs & $57.7 \pm 4.7$ & $56.7 \pm 4.7$ & $59.0 \pm 4.8$ & $58.2 \pm 4.8$ & $57.9 \pm 4.8$ \\
\hline BMI & $26.3 \pm 3.5$ & $25.1 \pm 4.3$ & $25.2 \pm 3.4$ & $23.6 \pm 3.6$ & $25.2 \pm 3.8$ \\
\hline Pack-yrs & $37.4 \pm 13.2$ & $32.0 \pm 10.4$ & $40.7 \pm 15.6$ & $35.0 \pm 12.0$ & $36.4 \pm 13.4$ \\
\hline FEV 1 L & $3.50 \pm 0.59$ & $2.57 \pm 0.44$ & $3.01 \pm 0.66$ & $2.15 \pm 0.49$ & $2.89 \pm 0.75$ \\
\hline FEV $_{1} \%$ & $99.0 \pm 14.1$ & $100.1 \pm 14.4$ & $85.3 \pm 16.7$ & $85.5 \pm 17.0$ & $93.3 \pm 16.9$ \\
\hline FEV $1 / F V C$ & $0.76 \pm 0.04$ & $0.76 \pm 0.04$ & $0.63 \pm 0.06$ & $0.64 \pm 0.06$ & $0.70 \pm 0.08$ \\
\hline PD15 $\mathrm{g} \cdot \mathrm{L}^{-1}$ & $98.4 \pm 19.7$ & $111.5 \pm 20.5$ & $87.0 \pm 15.6$ & $100.1 \pm 20.6$ & $99.2 \pm 21.0$ \\
\hline
\end{tabular}

Data are presented as mean $\pm \mathrm{SD}$, unless otherwise stated. BMI: body mass index; FEV1: forced expiratory volume in $1 \mathrm{~s}$; FVC: forced vital capacity; PD15: 15th percentile density.
Female sex was predictive of a higher PD15 at age 60 yrs $\left(17.3 \pm 0.6 \mathrm{~g} \cdot \mathrm{L}^{-1}, \mathrm{p}<0.001\right)$ and was associated with increased annual loss of lung density of $-0.3 \pm 0.1 \mathrm{~g} \cdot \mathrm{L}^{-1}(\mathrm{p}<0.001)$ (table 2 and fig. 1a). The sex difference at age 60 yrs from a similar mixed effects model using raw PD15 data without volume adjustment was $12.7 \pm 0.8 \mathrm{~g} \cdot \mathrm{L}^{-1}(\mathrm{p}<0.001)$, showing that the sex difference was not introduced by volume adjustment.

\section{Influence of smoking on CT lung density}

Smoking had a significant impact on lung density at age $60 \mathrm{yrs}$ and on the annual decline in lung density. Smoking is represented by two variables in the model, the accumulated previous smoking (pack-yrs) and current smoking status. The number of pack-yrs was a strong predictor of a higher PD15 at age 60 yrs. Compared with 20-30 pack-yrs, individuals with 3040 pack-yrs had an increased PD15 \pm SE level of $2.5 \pm 0.7 \mathrm{~g} \cdot \mathrm{L}^{-1}$ $(\mathrm{p}<0.001)$; and this was even higher in individuals with $>40$ pack-yrs, $5.5 \pm 0.8 \mathrm{~g} \cdot \mathrm{L}^{-1}(\mathrm{p}<0.001)$ (table 2$)$. There was no significant interaction between pack-yrs and age, thus the number of pack-yrs was not predictive of a steeper decline in PD15 (table 2 and fig. 1b).

In current smokers, the number of cigarettes smoked daily was a strong predictor of a higher PD15 compared with the reference group of ex-smokers and was PD15 \pm SE $8.98 \pm 0.73 \mathrm{~g} \cdot \mathrm{L}^{-1}$ $(\mathrm{p}<0.001)$ higher in those smoking 1-10 cigarettes per day; $10.33 \pm 0.71 \mathrm{~g} \cdot \mathrm{L}^{-1}(\mathrm{p}<0.001)$ higher in those smoking $11-20$ cigarettes per day; and $12.63 \pm 0.73 \mathrm{~g} \cdot \mathrm{L}^{-1}(\mathrm{p}<0.001)$ higher in those smoking $>20$ cigarettes per day (table 2 ).

Continuous smoking during the study was also a strong predictor of accelerated annual decline in PD15. Compared with the reference group of former smoking males, participants smoking 1-10 cigarettes daily had an additional decline in PD15 \pm SE of $-0.28 \pm 0.09 \mathrm{~g} \cdot \mathrm{L}^{-1}(\mathrm{p}<0.01)$; those smoking $11-20$ cigarettes daily had an additional decline of $-0.48 \pm 0.08 \mathrm{~g} \cdot \mathrm{L}^{-1}(\mathrm{p}<0.001)$; and those smoking $>20$ cigarettes a day had an additional decline of $-0.42 \pm 0.09 \mathrm{~g} \cdot \mathrm{L}^{-1}(\mathrm{p}<0.001)$ (table 2 and fig. $\left.1 \mathrm{c}\right)$.

\section{Influence of AFO on CT lung density}

Severity of AFO according to GOLD stages was a strong predictor of lower PD15 at age 60 yrs: GOLD stage I PD15 \pm SE $-1.42 \pm 0.70 \mathrm{~g} \cdot \mathrm{L}^{-1} \quad(\mathrm{p}=0.042) ;$ GOLD stage II $-6.30 \pm 0.92 \mathrm{~g} \cdot \mathrm{L}^{-1}$ $(\mathrm{p}<0.001)$; and GOLD stage III $-16.99 \pm 2.73 \mathrm{~g} \cdot \mathrm{L}^{-1}(\mathrm{p}<0.001)$ (table 2). Likewise, severity of airway obstruction at baseline was a strong predictor of the magnitude of decline in PD15: GOLD stage I $-0.21 \pm 0.08 \mathrm{~g} \cdot \mathrm{L}^{-1}(\mathrm{p}=0.01)$; GOLD stage II $-0.48 \pm$ $0.11 \mathrm{~g} \cdot \mathrm{L}^{-1} \quad(\mathrm{p}<0.001)$; and GOLD stage III $-0.50 \pm 0.30 \mathrm{~g} \cdot \mathrm{L}^{-1}$ $(p=0.10)$ (table 2 and fig. 1d). There was no significant interaction between pack-yrs and the severity of AFO (GOLD stages).

\section{DISCUSSION}

Analysis of this large cohort from the DLCST shows that age, sex, smoking habits and the presence of AFO have a significant impact on lung density. The presence of AFO is in addition associated with the largest annual loss in lung density. Furthermore, female sex and the number of cigarettes smoked daily throughout the trial are associated with an increased annual loss in lung density. Given the design of the trial, we have no data on lung density changes in healthy neversmokers; therefore, the reference group comprises ex-smokers without AFO. The highly significant time trend in the reference 


\begin{tabular}{|c|c|c|c|c|c|}
\hline \multirow[t]{2}{*}{ Reference group } & \multirow[t]{2}{*}{ Baseline $\mathbf{n}$} & \multicolumn{2}{|c|}{ Level of PD15 $\mathrm{g} \cdot \mathrm{L}^{-1}$} & \multicolumn{2}{|c|}{ Annual change of $\mathrm{PD}^{-1} 5^{\pi} \mathrm{g} \cdot \mathrm{L}^{-1} \cdot \mathrm{yr}^{-1}$} \\
\hline & & Estimate $\pm \mathrm{SE}$ & $p$-value & Estimate $\pm \mathrm{SE}$ & $p$-value \\
\hline Explanatory variables & 55 & $72.59 \pm 0.83$ & & $-0.33 \pm 0.09$ & $<0.001$ \\
\hline Females & 845 & $17.28 \pm 0.62$ & $<0.001$ & $-0.28 \pm 0.07$ & $<0.001$ \\
\hline \multicolumn{6}{|l|}{ Pack-yrs } \\
\hline $20-30$ & 725 & Reference & & Reference & \\
\hline $30-40$ & 621 & $2.46 \pm 0.73$ & $<0.001$ & $-0.07 \pm 0.08$ & 0.407 \\
\hline$>40$ & 571 & $5.52 \pm 0.78$ & $<0.001$ & $-0.08 \pm 0.09$ & 0.358 \\
\hline$>20$ & 451 & $12.63 \pm 0.73$ & $<0.001$ & $-0.42 \pm 0.09$ & $<0.001$ \\
\hline \multicolumn{6}{|l|}{ GOLD } \\
\hline No AFO & 1074 & Reference & & Reference & \\
\hline Stage I & 548 & $-1.42 \pm 0.7$ & 0.042 & $-0.21 \pm 0.08$ & 0.010 \\
\hline Stage ॥ & 269 & $-6.30 \pm 0.92$ & $<0.001$ & $-0.48 \pm 0.11$ & $<0.001$ \\
\hline Stage III & 26 & $-16.99 \pm 2.73$ & $<0.001$ & $-0.50 \pm 0.3$ & 0.103 \\
\hline
\end{tabular}

PD15: 15th percentile density; GOLD: Global Initiative for Chronic Obstructive Lung Disease. ${ }^{\#}$ : the effects are estimates of the explanatory variables on the annual loss of PD15 $\left(\mathrm{g} \cdot \mathrm{L}^{-1} \cdot \mathrm{yr}^{-1}\right.$, interaction with age) in excess of the reference group. ${ }^{\circ}$ : at age $60 \mathrm{yrs}$.

group probably indicates an age-related decline in lung density, a finding supported by earlier cross-sectional pathological and radiological studies [20, 21].

Based on 8,063 CT scans from 2,042 participants we have constructed a statistical model describing the influence of different factors including smoking habits on lung density. The robustness of the model is indicated by highly significant coefficients for the explanatory variables (most $\mathrm{p}<0.001$ ), and the model is also fairly comprehensive including all significant interaction terms. Smoking is represented by two variables in the model, that is the accumulated previous smoking (packyrs) and current smoking status (0 cigarettes per day, i.e. exsmoker, 1-10 cigarettes per day, 11-20 cigarettes per day and $>20$ cigarettes per day), and both these variables were strongly correlated to lung density at age $60 \mathrm{yrs}$. Three additional covariates were included in the model: age, sex and GOLD stage. The clinical interpretation of the model is somewhat simplified by the fact that only interaction terms involving age were statistically significant as can be seen in the different slopes in figure 1. Possible clinical interpretations of the model for each variable are discussed next.

Lung density in females was significantly higher than in males, and there was a significant interaction with age that is the mean annual loss of lung tissue was higher for females than for males (table 2 and fig. 1a). In patients with COPD, a number of studies reported more severe emphysema in males [22-24] and more rapid progression of emphysema in females $[9,25]$. It is generally thought that biological differences make females more susceptible to the harmful effects of smoking than males [26].
In a recent study, SvERZILLATI et al. [25] reported certain morphological differences in emphysema suggesting a sex-related phenotype characterised by smaller emphysema lesions less prominent in the lung core. In order to rule out the possibility that the sex-related difference in PD15 was an artefact introduced by the volume adjustment, the analysis was repeated on raw PD15 data. The difference was $13 \mathrm{~g} \cdot \mathrm{L}^{-1}$, which indeed reflects a large difference between males and females that might be attributed to lower lung volumes in females. Independent of the burden of smoking and the presence of COPD, females have a significantly larger decline in PD15 than males; however, this difference does not seem to influence prognosis as females with COPD have better survival rates than males [27].

While the influence of sex on lung density seems to be straightforward, the influence of smoking is a bit more complex. There seem to be two pathological influences, one of inflammation and some degree of scarring (fibrosis) causing increased lung density, and in a substantial minority of individuals one of emphysema and reduced lung density. For the amount of previous smoking (i.e. pack-yrs) the model indicated a proportional increase in lung density (fig. 1b). The increase per pack-yr was modest $\left(0.2-0.3 \mathrm{~g} \cdot \mathrm{L}^{-1}\right)$, but highly significant $(p<0.001)$, and no significant interaction was observed with the other explanatory variables including age. This increase in lung density may be counter-intuitive given the fact that smoking causes emphysema that implies loss of lung tissue. As will be discussed in more details later, low lung density at age $60 \mathrm{yrs}$ was only observed in the presence of obstructive lung disease (GOLD stages) in our model, and this was not related to the previously smoked pack-yrs (i.e. the 
interaction between pack-yrs and GOLD stages was not significant). People without AFO who had stopped smoking prior to inclusion demonstrated increasing lung density for each pack-yr they had smoked. The limitation of our study was that we did not include subjects with $<20$ pack-yrs, and therefore, we have no information on lung density for such people. However, based on the fairly linear relationship between pack-yrs and lung density observed in our study population, it is tempting to assume that this relationship continues below 20 pack-yrs indicating that never smokers have less dense lungs than ex-smokers without COPD. Other investigators found that the risk of emphysema progression is higher in current than in ex-smokers; but nevertheless in line with our findings they reported no significant impact of packyrs on emphysema progression [28].

A possible explanation for this interesting finding could be the microscopic damage to lung tissue due to the noxious effect of smoking with inflammation and microscopic scarring (fibrosis). There is clear evidence that smoking induces an inflammatory reaction in the lung, which is evident even in young smokers [29]. Inflammation is associated with or followed by a certain degree of microscopic fibrosis. AUERBACH et al. [30] in a microscopic study of over 1,800 autopsy lungs reported that the degree of fibrosis increased with increasing amounts of cigarette smoking. More recently, researchers have shown pathological and radiological evidence of interstitial fibrosis in smokers even in the absence of clinical evidence of interstitial lung disease [31, 32]. Another possible explanation for this proportional increase in lung density with the number of packyrs regardless of the presence of COPD is irreversible selfperpetuating inflammatory changes in the lung in smokers.

Current smoking increased lung density at age $60 \mathrm{yrs}$ and at the same time interacted with age indicating an aggravated annual loss of lung density (fig. 1c). This finding is supported by BELLOMI et al. [28], who found that the percentage of emphysema over a 2-yr period was significantly higher in current than in exsmokers. The coefficients of the three smoking categories (1-10 cigarettes per day, 11-20 cigarettes per day and >20 cigarettes per day) showed a fairly clear dose-response relationship between the number of cigarettes smoked daily and both lung density at age 60 yrs and the annual loss of lung density. These opposing effects of smoking are not surprising, and are probably explained by smoking induced inflammation with increased movement of plasma and inflammatory cells from the circulation into the lung interstitium in the short-term and in the long-term remodelling and loss of lung tissue. The opposing effects of smoking on lung density may also explain the inconsistent results of previous cross-sectional studies [7-9]. In order to avoid large inter-individual variations, CT-measurements of participants who changed their smoking habits were excluded from the date of change. This might have introduced a selection bias, if individuals with rapidly declining lung density are more likely to quit smoking.

It is interesting that less than half of our participants (44\%) had AFO. The presence of airways obstruction (GOLD stage 1-3) was the only explanatory variable that was related to low lung density at age $60 \mathrm{yrs}$ and, independent of smoking, airway obstruction implied an exaggerated annual loss of lung density (fig. 1d). For both lung density at age $60 \mathrm{yrs}$ and the annual loss of lung density, the relation had the character of a dose-response relationship. This is interesting and the clinical interpretation is obvious given that parenchymal destruction with loss of lung tissue (emphysema) is an important pathological mechanism in the development of COPD. There was no significant interaction between GOLD stages and prior or current smoking, which might suggest that this pathological process continued even after patients had stopped smoking, while continued smoking further aggravated the annual loss of lung density in patients with COPD.

Our study had some limitations. Partially excluding data from patients who changed their smoking habit may have introduced a selection bias because they might have stopped smoking because of rapid decline in lung density. However, smoking cessation induces sudden decline in lung density [12]. Due to the instructions during scanning, some participants may have performed a Valsalva manoeuvre, which affects lung perfusion by increasing intrathoracic pressure and decreasing venous blood flow. Variations in lung perfusion might have a potential influence on the reported results [33]. Finally, it would have been interesting to correlate the results on density with respiratory symptoms, but these data are currently not available.

In conclusion, females had a higher lung density and significantly larger annual decline than males. Both previous smoking (pack-yrs) and current smoking, independent of each other, related to an increase in lung density at age $60 \mathrm{yrs}$, although current smoking also seemed to increase the annual loss of lung density. Reduced lung density at age 60 yrs was only observed in individuals with AFO (GOLD stage 1-3). Furthermore, these individuals with AFO showed an exaggerated annual loss of lung density that, although more tempered, continued after they had stopped smoking.

\section{SUPPORT STATEMENT}

The Danish Lung Cancer Screening Trial received financial support from the Danish Ministry of Interior and Health. The densitometric measurements reported in this paper were supported by unrestricted grants from the Danish Council for Strategic Research under the Programme Commission for Nanoscience and Technology, Biotechnology and IT (NABIIT) and from AstraZeneca R\&D, Sweden.

\section{STATEMENT OF INTEREST}

Statements of interest for A. Dirksen, M. de Bruijne and for the study itself can be found at www.erj.ersjournals.com/site/misc/statements. xhtml

\section{REFERENCES}

1 Lopez AD, Shibuya K, Rao C, et al. Chronic obstructive pulmonary disease: current burden and future projections. Eur Respir J 2006; 27: 397-412.

2 Müller NL, Staples CA, Miller RR, et al. "Density mask". An objective method to quantitate emphysema using computed tomography. Chest 1988; 94: 782-787.

3 Gould GA, MacNee W, McLean A, et al. CT measurements of lung density in life can quantitate distal airspace enlargement - an essential defining feature of human emphysema. Am Rev Respir Dis 1988; 137: 380-392.

4 Gevenois PA, de Maertelaer V, De Vuyst P, et al. Comparison of computed density and macroscopic morphometry in pulmonary emphysema. Am J Respir Crit Care Med 1995; 152: 653-657. 
5 Kinsella M, Muller NL, Abboud RT, et al. Quantitation of emphysema by computed tomography using a "density mask" program and correlation with pulmonary function tests. Chest 1990; 97: 315-321.

6 Gould GA, Redpath AT, Ryan M, et al. Lung CT density correlates with measurements of airflow limitation and the diffusing capacity. Eur Respir J 1991; 4: 141-146.

7 Kalef-Ezra J, Karantanas A, Tsekeris P. CT measurement of lung density. Acta Radiol 1999; 40: 333-337.

8 Camiciottoli G, Cavigli E, Grassi L, et al. Prevalence and correlates of pulmonary emphysema in smokers and former smokers. A densitometric study of participants in the ITALUNG trial. Eur Radiol 2009; 19: 58-66.

9 Grydeland TB, Dirksen A, Coxson HO, et al. Quantitative computed tomography: emphysema and airway wall thickness by sex, age and smoking. Eur Respir J 2009; 34: 858-865.

10 Wright JL, Hobson JE, Wiggs B, et al. Airway inflammation and peribronchiolar attachments in the lungs of nonsmokers, current and ex-smokers. Lung 1988; 166: 277-286.

11 Ashraf H, Lo P, Shaker SB, et al. Short-term effect of changes in smoking behaviour on emphysema quantification by CT. Thorax 2011; 66: 55-60.

12 Shaker SB, Stavngaard T, Laursen LC, et al. Rapid fall in lung density following smoking cessation in COPD. COPD 2011; 8: 2-7.

13 Pedersen JH, Ashraf H, Dirksen A, et al. The Danish randomized lung cancer $\mathrm{CT}$ screening trial - overall design and results of the prevalence round. J Thorac Oncol 2009; 4: 608-614.

14 Dirksen A. Monitoring the progress of emphysema by repeat computed tomography scans with focus on noise reduction. Proc Am Thorac Soc 2008; 5: 925-928.

15 Shaker SB, Dirksen A, Ulrik CS, et al. The effect of inhaled corticosteroids on the development of emphysema in smokers assessed by annual computed tomography. COPD 2009; 6: 104-111.

16 Stolk J, Putter H, Bakker EM, et al. Progression parameters for emphysema: a clinical investigation. Respir Med 2007; 101: 1924-1930.

17 Lo P, Sporring J, Ashraf H, et al. Vessel-guided airway segmentation based on voxel classification. Med Image Anal 2010; 14: 527-538.

18 Stoel BC, Putter H, Bakker ME, et al. Volume correction in computed tomography densitometry for follow-up studies on pulmonary emphysema. Proc Am Thorac Soc 2008; 5: 919-924.

19 Quanjer PH, Tammeling GJ, Cotes JE, et al. Lung volumes and forced ventilatory flows. Report Working Party Standardization of Lung Function Tests, European Community for Steel and Coal.
Official Statement of the European Respiratory Society. Eur Respir J 1993; 6: Suppl. 16, S5-S40.

20 Gillooly M, Lamb D. Airspace size in lungs of lifelong nonsmokers: effect of age and sex. Thorax 1993; 48: 39-43.

21 Gevenois PA, Scillia P, de Maertelaer V, et al. The effects of age, sex, lung size, and hyperinflation on CT lung densitometry. AJR Am J Roentgenol 1996; 167: 1169-1173.

22 Camp PG, Coxson HO, Levy RD, et al. Sex differences in emphysema and airway disease in smokers. Chest 2009; 136: 1480-1488.

23 Dransfield MT, Washko GR, Foreman MG, et al. Gender differences in the severity of CT emphysema in COPD. Chest 2007; 132: 464-470.

24 Martinez FJ, Curtis JL, Sciurba F, et al. Sex differences in severe pulmonary emphysema. Am J Respir Crit Care Med 2007 1, 176: 243-252.

25 Sverzellati N, Calabrò E, Randi G, et al. Sex differences in emphysema phenotype in smokers without airflow obstruction. Eur Respir J 2009; 33: 1320-1328.

26 Prescott E, Bjerg AM, Andersen PK, et al. Gender difference in smoking effects on lung function and risk of hospitalization for COPD: results from a Danish longitudinal population study. Eur Respir J 1997; 10: 822-827.

27 de Torres JP, Cote CG, López MV, et al. Sex differences in mortality in patients with COPD. Eur Respir J 2009; 33: 528-535.

28 Bellomi M, Rampinelli C, Veronesi G, et al. Evolution of emphysema in relation to smoking. Eur Radiol 2010; 20: 286-292.

29 Niewoehner DE, Kleinerman J, Rice DB. Pathologic changes in the peripheral airways of young cigarette smokers. N Engl J Med 1974; 291: 755-758.

30 Auerbach O, Garfinkel L, Hammond EC. Relation of smoking and age to findings in lung parenchyma: a microscopic study. Chest 1974; 65: 29-35.

31 Lederer DJ, Enright PL, Kawut SM, et al. Cigarette smoking is associated with subclinical parenchymal lung disease: the MultiEthnic Study of Atherosclerosis (MESA)-lung study. Am J Respir Crit Care Med 2009 1, 180: 407-414.

32 Katzenstein AL, Mukhopadhyay S, Zanardi C, et al. Clinically occult interstitial fibrosis in smokers: classification and significance of a surprisingly common finding in lobectomy specimens. Hum Pathol 2010; 41: 316-325.

33 Hughes J, Glazier J, Maloney J, et al. Effect of lung volume on the distribution of pulmonary blood flow in man. Respir Physiol 1968; 4: 58-72. 